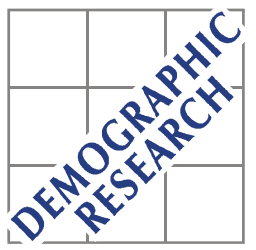

Demographic Research a free, expedited, online journal

of peer-reviewed research and commentary in the population sciences published by the Max Planck Institute for Demographic Research

Konrad-Zuse Str. 1, D-18057 Rostock · GERMANY

www.demographic-research.org

DEMOGRAPHIC RESEARCH

VOLUME 24, ARTICLE 7 PAGES 179-200
PUBLISHED 02 FEBRUARY 2011

http://www.demographic-research.org/Volumes/Vol24/7/

DOI: 10.4054/DemRes.2011.24.7

Reflexion

\title{
Should governments in Europe be more aggressive in pushing for gender equality to raise fertility? The first "YES"
}

\section{Laurent Toulemon}

This publication is part of the Special Collection "Rostock debate on demographic change", organized by Guest Editor Laura Bernardi.

(C) 2011 Laurent Toulemon.

This open-access work is published under the terms of the Creative Commons Attribution NonCommercial License 2.0 Germany, which permits use, reproduction \& distribution in any medium for non-commercial purposes, provided the original author(s) and source are given credit.

See http:// creativecommons.org/licenses/by-nc/2.0/de/ 


\section{Table of Contents}

$1 \quad$ Preliminary questions $\quad 180$

1.1 Is fertility too low in Europe? 180

1.2 Should governments take action to change fertility? 182

$1.3 \quad$ How should population policies be assessed? Using what criteria? 184

$1.4 \quad$ Should demographers act as "experts"? 187

2 When the question comes to the floor 189

$\begin{array}{ll}2.1 & 189\end{array}$

$\begin{array}{ll}2.2 & 191\end{array}$

3 Governments in Europe should be more aggressive in pushing for 192 gender equality to raise fertility

3.1 The content of pronatalist policies 192

3.2 Gender equality as a pathway to consensus 193

3.3 Conclusion: Be brave, but be careful 195

$\begin{array}{ll}\text { References } & 197\end{array}$ 


\title{
Should governments in Europe be more aggressive in pushing for gender equality to raise fertility? \\ The first "YES" 1
}

\author{
Laurent Toulemon ${ }^{2}$
}

\begin{abstract}
Together with three colleagues, I have been asked by the MPIDR to debate the following question: "Should governments in Europe be more aggressive in pushing for gender equality to raise fertility? Setting aside the "lighthearted" side of this "Rostocker Debate," (12 minutes for each speech, one minute for each comment), I saw this as a good opportunity to think about the stakes behind the question.

In order to address this complex issue, it is necessary to think about the many "preliminary questions" that we have to ponder before responding: Why should fertility be raised? Are political measures legitimate? Are they efficient? On what basis are we qualified to give "expert" opinions on such a topic?

When the question comes to the fore, we as scholars are sometimes asked to provide an answer. It would, of course, be more comfortable not to answer, but our interlocutors (politicians, journalists, teachers, and also funding agencies) often want a definite response one way or the other. Even though our position may be a matter of politics as well as a matter of science, we must give an answer.

The empirical evidence shows that European countries where gender inequality is lower are also the countries where fertility is the highest. This is the evidence-based response that we can give to that question. European countries need to find a new equilibrium after the end of the baby boom period, when gender equality was very low. In all countries, the empowerment of women is underway, thanks to the economic independence given by work-related income. Increasing gender equality is an efficient way to reduce the opportunity costs of having and raising children, and thus to increase fertility.
\end{abstract}

\footnotetext{
${ }^{1}$ This is the second of two "yes" positions taken from the "Rostock Debate on Demographic Change" held at the Max Planck Institute for Demographic Research on 21 February 2006.

${ }^{2}$ Institut national d'études démographiques (INED) E-mail: toulemon@ined.fr
} 
Finally, "pushing for gender equality" may have many positive effects other than raising fertility, and has few negative side effects. Gender equality is thus a convenient political aim per se; an institutional goal which leaves many political questions open. So, yes, we agree that governments in Europe should be more aggressive in pushing for gender equality to raise fertility!

\section{Preliminary questions}

The question of whether governments in Europe should be more aggressive in pushing for gender equality to raise fertility is, indeed, very complicated. First, the wording of the question is based on two implicit assumptions which have to be tested: that fertility in Europe should increase, and that governments should act to raise fertility. Second, our answer as scholars is also based on two implicit assumptions: that we are qualified, and that our scientific knowledge makes our answer meaningful; and that we have the political legitimacy to answer the question.

None of these four assumptions is obviously true. Before addressing the main point, it is thus necessary to tackle these four preliminary questions about the diagnosis of fertility levels, the legitimacy of state action, the actual efficiency of pronatalist policies, and, last but not least, our legitimacy as "experts."

\subsection{Is fertility too low in Europe?}

\subsubsection{Where is the limit: $2.1,1.8$, or 1.5 ?}

The answer to the question of whether fertility is too low seems simple: the replacement level of 2.1 children per woman has been made very popular by demographers. If the total fertility rate is lower than this limit, then the net reproduction rate (number of daughters per woman) is lower than one, and the population decreases; if it is higher than 2.1, the population increases.

The limit of 2.1 is sometimes likened to the sea level: it does not make any difference whether you are just below or well below, because if you want to breathe you must be at this level or above. Yet pronatalist demographers living in countries where fertility is below 1.3 children per women often say that 1.8 would be good enough, or that even 1.5 would be sufficient (Golini 2003; McDonald 2003, 2005). To give a diagnosis on the level of fertility, we must have a precise criterion in mind. 


\subsubsection{Stationarity as a target}

To determine whether fertility is too low or too high, we need to have an optimum level in mind. Let us assume that having a stationary population (constant size, stable age structure, constant number of births) is the target. As mortality is still declining, and is almost negligible before the end of childbearing ages, our optimum could be a quasistationary population with a constant population size before the age of 50, and a slowly increasing population at older ages due to the mortality decline.

Of course other targets could be suggested, such as positive or negative long-term or short-term population growth, so the idea of stationarity is not the one and only possible target. An increasing population may be considered to be a driver of economic growth, or a burden for child care institutions.

There is no room here to discuss the other possible fertility indices: cohort fertility differs from period fertility when fertility timing is changing, the number of births also depends on the number of parents-to-be aged between 20 and 40, the transition to a stationary population is not immediate, etc. We may assume that a period TFR of 2.1 is the target.

\subsubsection{Is the birth deficit an individual problem or a population problem?}

Two kinds of arguments can be used to justify the need to raise fertility. On the one hand, couples want to have more children; on the other hand, countries are facing a birth deficit. Note that the first argument, even if very common, is not necessarily true. In order to be consistent, the comparison between total fertility and ideal family size would compare the latter to the cohort fertility of women who ever lived as a family. During the baby boom period, the number of births was much higher than ideal fertility. In recent years, the gap has been low in some European countries, like France and Germany (Toulemon and Leridon 1999; Goldstein, Lutz, and Testa 2004), where the pronatalist view is currently common among politicians. In France, the fertility level is exactly at the replacement level, when migration is taken into account (Toulemon and Robert-Bobée 2006). In Germany, the responses to survey questions about ideal family size indicate that the mean ideal number is low, with a large proportion of young adults answering that a childless family is the ideal size; and actual period fertility is accordingly low. Moreover, fertility intentions are not constant over the life course, and many couples have more or fewer children than expected (Quesnel-Vallée and Morgan 2003).

Another approach is to focus on the perceived interest of the country as a whole, irrespective of the desires of couples. These two criteria currently converge in some 
countries, but not everywhere. The rationale for a demographic policy may not necessarily be to fulfil the wishes of couples, as there is no reason why the summing of individual behaviors should lead to an optimum. If we have an optimum in mind, we may argue that couples who move in the "right direction," or who want to do so, must be helped, but this may be contrary to other political aims, such as equity. It might be better to think in terms of institutional settings which lead to an "acceptable" level of fertility, not in terms of helping some people specifically.

\subsubsection{Conclusion: It's OK to say that fertility is certainly not too high...}

Going back to our preliminary question, we may agree that almost all population projections anticipate a population decline in all European countries except for Ireland and France, while the world population will increase by some $50 \%$ in the next 50 years (Eurostat 2006; United Nations 2007). Thus, even if the question of whether fertility is currently too low is by no means straightforward, we may agree on the diagnosis that fertility in Europe is not too high, and that in some countries it may be as too low.

\subsection{Should governments take action to change fertility?}

Let us assume that the fertility level is currently too low in Europe. This takes us to our second preliminary question: Should governments take action to change fertility?

\subsubsection{Yes, but only if we are in a dangerous situation}

Here we could add another criterion: fertility is a private matter, and governments should, as far as possible, avoid interfering (van de Kaa 2006). An exception could be made if it is determined that the country (or the continent) is facing a dangerous situation, because couples are behaving in a way that threatens society.

The question then moves from "Is fertility too low?" to "Is fertility so low that the state is entitled to interfere?" As previously noted for the target level of fertility, the "limit" value under which fertility is assumed to be "much too low" is sometimes set at 1.3 (Kohler, Billari, and Ortega 2002), and sometimes at 1.5 (Lutz and Skirbekk 2005; McDonald 2006), while 1.8 is considered a tolerable, if not optimal value (Golini 2003). 


\subsubsection{Are European countries in a dangerous situation? Halving time, migration}

Table 1 below may be useful for determining what kind of diagnosis may be derived from each level of fertility. The first line presents several levels of the TFR, from 2.0 to 1.0 , together with the value of 2.08 , which corresponds to a constant population over the long run, in the absence of migration. ${ }^{3}$ The net reproduction rate $R_{0}$ represents the ratio of the cohort size of daughters to the cohort size of mothers. For a mean age at childbirth of 30 years, each value of the TFR may be associated with an instant growth rate $r{ }^{4}$ Two more concrete descriptions of this growth rate are presented in Table 1 . The first is the halving time $T$, or the length of time necessary for the population size to halve. ${ }^{5}$ With a TFR of 2.08 , the population is constant $(r=0)$ and the halving time is infinite. With a TFR of 1.9 (the value assumed in the central fertility scenario of the last official population projection in France, see Robert-Bobée 2006), the halving time is 230 years; while with a TFR of 1.3 (like in Germany), it is 44 years. The level of urgency is clearly not the same in both countries (Morgan and Taylor 2006).

Table 1: Halving time and net migration (as a proportion of births) necessary to maintain stationarity, for several values of the Total Fertility Rate

\begin{tabular}{lcccccccc}
\hline Total fertility rate (TFR) & 2.08 & 2.0 & $\mathbf{1 . 9}$ & 1.7 & 1.5 & $\mathbf{1 . 3}$ & 1.1 & 1.0 \\
Net reproduction rate $R_{0}$ & 1 & 0.96 & $\mathbf{0 . 9 1}$ & 0.82 & 0.72 & $\mathbf{0 . 6 3}$ & 0.53 & 0.48 \\
Mean age at childbirth & 30 & 30 & $\mathbf{3 0}$ & 30 & 30 & $\mathbf{3 0}$ & 30 & 30 \\
Instant $r$ (per 1000) & 0 & -1.3 & $\mathbf{- 3 . 0}$ & -6.7 & -10.9 & $\mathbf{- 1 5 . 7}$ & -21.2 & -24.4 \\
Halving time $T$ (years) & infinite & 530 & $\mathbf{2 3 0}$ & 103 & 64 & $\mathbf{4 4}$ & 33 & 28 \\
"Missing" births (\%) & 0 & 3.8 & $\mathbf{8 . 7}$ & 18.3 & 27.9 & $\mathbf{3 7 . 5}$ & 47.1 & 51.9 \\
Net migration/Births (\%) & 0 & 4.0 & $\mathbf{9 . 5}$ & 22.4 & 38.7 & $\mathbf{6 0 . 0}$ & 89.1 & 108.0 \\
\hline
\end{tabular}

Another way to interpret the different values of the TFR is to estimate the proportion of missing births compared to the target of 2.08, and to transform this proportion into the proportion of net migrants per 100 births necessary to compensate

\footnotetext{
${ }^{3}$ With a sex ratio at birth of 105 boys for 100 girls and a survival probability of $98.6 \%$ between birth and reproductive age, 208 births correspond to three children dying, 105 men and 100 women still alive at reproductive age.

${ }^{4}$ The formula is simply $r=\frac{\ln \left(R_{0}\right)}{a}$, where $r$ is the instant growth rate, $R_{0}$ the net reproduction rate, and $a$ the mean age at childbearing. The formula can be reversed as $R_{0}=\exp (\mathrm{ra})$. It is an approximation, assuming that all children are born to mothers of age $a$.

${ }^{5}$ In a stable population $T=\frac{-\ln (2)}{r}$
} 
for the birth deficit (assuming that migrants enter before childbearing age or come with their children) and to maintain population size at a constant level. With a TFR of 1.9, $8.7 \%$ births are "missing," and a net migration equal to $9.5 \%$ of the number of births is enough to make up the deficit. With a TFR of 1.3 , net migration must reach $60 \%$ of the number of births in order to maintain stationarity.

The TFR is below 2.08 in France and Germany, but the diagnosis for the two countries is very different: in France the situation is near to stationarity, while in Germany the decline could be rapid if the current value of the TFR remains constant in the future.

\subsubsection{Pro and cons of population policies}

Let us now assume that the level of fertility is considered to be too low, making it useful or necessary to try to raise it. The pro and cons of all possible measures must be carefully evaluated, taking into account not only the level of fertility (the number of births), but also other consequences of population policies, including their side effects.

\subsection{How should population policies be assessed? Using what criteria?}

Population policies must be assessed on a cost-benefit basis. This involves estimating the "cost" of a declining population, in order to quantify the benefit derived from an additional birth. The costs of population policies must also be determined.

\subsubsection{Extra births per euro spent?}

A simple criterion would be to evaluate the costs of several policies and to estimate the most efficient in terms of extra births per euro spent. This would undoubtedly lead to policies encouraging poor couples to have many children. But the state would then have to help families raise their children, and it could be argued that children are a better investment, in terms of human capital, if they grow up with highly educated and wealthy parents... The classic alternative between equity and efficiency also comes to mind: Do we want to maximize efficiency by helping some families have many children, or to promote equity by helping all families? The sensitivity of the total number of births to one or another measure may be estimated, though with much uncertainty (Gauthier 2007); but assessing the side effects of each measure is impossible. 


\subsubsection{Should public support be proportional to family income, equal for all children, or targeted to "poor" children?}

Equity is not a simple question. The current situation in Europe is very diverse in terms of redistribution between individuals and families, exhibiting three contrasting patterns. In the United Kingdom, policies favoring families and children are primarily focused on poor families, and benefits are inversely proportional to family income. In the Nordic countries, the rationale is that children must be taken care of irrespective of their family's characteristics, such as parental income or the number of children. Public goods such as kindergartens and schools are preferred over monetary benefits, and the notion of equity leads to the idea that all children must be helped in the same way. In France, the state helps families, not children. The family policy is seen as "universal," and some measures take into account the fact that children are more expensive when they live in a rich family. Thus population policy focuses on "horizontal" redistribution, while social policy deals with "vertical" redistribution. The "horizontal" redistribution objective means that, for each specific family, the increase in expenses (and the income decline due to opportunity costs) must be compensated for, so that a family with children can maintain their standard of living relative to a "similar" family with fewer children. The consequence of that vision of equity is that the state must help rich families more, in absolute terms, than poor families. The French quotient familial for income tax (Aglietta, Blanchet, and Héran 2002) or parental leave allowance proportional to the salary before pregnancy are two examples of such policies. The former is based on the notion of "equity" in terms of the capacity to contribute to state expenses through the income tax system; the latter is based on an insurance rationale.

\subsubsection{Some policies tend to increase female labor force participation, others tend to lower it}

Among many other possible alternatives, the question of female labor force participation is a current issue, and is relevant for this debate. Some policy measures facilitate career interruptions, encouraging more parents (mostly mothers, in practice) to stay at home to raise their young children; while other measures, by contrast, make it easier for parents to stay on at work, since other adults are paid to take care of the young children within a public or private system of child care. This kind of choice cannot be based purely on a "cost-benefit" balance, as diverse aspects of social organization are involved.

The benefits may be measured not only in terms of additional births. For instance, extensive nursery day care provision may ease the burden of raising young children, 
and lead to additional births; it may also be considered a way to improve the "quality" of children in terms of literacy, social interaction, etc. In France there is a consensus of opinion that nursery school is good for young children, at least after the age of three, while in Germany it is believed that children need their mother to take care of them fulltime up to a higher age.

\subsubsection{All of the consequences of a population policy must be taken into account}

More generally, the consequences of any pronatalist policy are numerous, and must be thought of not only in terms of efficiency, but also in terms of equity. They may take into account norms and habits in order to increase their acceptability, or be based on a political will to change these norms and habits. This is true for any policy measure, but the rationale for a pronatalist policy is broad, and a variety of approaches can be envisaged, with very different side effects.

\subsubsection{Other policies may have an impact on fertility}

Policy measures may have an impact on the number of births, even if their aim is not linked to fertility. Two common examples are housing and education policies: extending the housing market so that more young people can set up home would probably increase young adults' fertility, but the improvement of their housing conditions can be viewed as an objective per se. The same is true for the education of young children. In France, for instance, the initial political ambition of sending all children to school has been transformed into an ambition to enroll children in school as early as possible. The rationale is that if children benefit from a public system of care and education early in life, social inequalities will decline when efforts are made to give the same opportunities to all children. An indirect effect of such a system is that the parents can more easily go back to work when their children are two or three years old. And this probably encourages them to have more children, despite the absence of any pronatalist goal attached to this measure. In the year 2000, the proportion of children aged three not attending school was $1 \%$ in France, compared to $22 \%$ in Germany (Périvier 2004). This undoubtedly makes a difference in terms of opportunity costs for mothers. 


\subsubsection{Other population policies: Health, mortality, and migration}

Last but not least, a population policy may have aims other than that of increasing the number of children, such as improvements in health care and a reduction in premature deaths. The rationale of these goals is very obvious and incontestable. While the notion of an optimal number of births has to be defined, for deaths the equation is more straightforward: the fewer the better. A migration policy may also be formulated to facilitate or to restrict entries or departures from a country.

\subsubsection{Conclusion: A non-demographic issue}

In conclusion, if policies are viewed as actions to be judged on their merits, then the questions of whether or not to implement pronatalist policies and the assessment of their consequences appear to be not demographic, but political issues.

\subsection{Should demographers act as "experts"?}

As a consequence, demographers may not be the best people to give expert advice to politicians. Population projections are useful for evaluating the long-term consequences of any combination of fertility, mortality, and migration behaviors. For instance, demographers can make population projections and forecast population aging, a planetary phenomenon due to the decline of fertility. The current aging process in Europe is also due to the baby boom in the 1950s, and to the decline in mortality. Demographers can show that aging is unavoidable, and that the current levels of fertility could lead to a population decline in the future. But are they able to say whether this or that trend is good or bad? And, assuming that they have identified a likely trend to be a problem, can they offer efficient solutions?

\subsubsection{Bad and good memories of expert opinions and population policies (contraception, abortion)}

Looking back at the past, the answer is definitely "no": demographers are no better than others at offering effective solutions to population problems. In the beginning of the last century, demographers did not foresee the baby boom and the fear of population decline proved partially unfounded. Many demographers were firm opponents of abortion and 
contraception, and they were mostly wrong about their "scientific" assumptions (Teitelbaum and Winter 1985).

\subsubsection{Diagnosis at the macro level and individual freedom}

A recent example of a demographic question that was addressed by demographers, and which led to the formation of non-demographic opinions, is a recent debate about whether parents should be allowed to choose the sex of their children. The debate was organized by the IUSSP at its International Population Conference in Tours (IUSSP 2005). The risk of gender imbalance is known, and some countries already have a major imbalance in the sex ratio at birth. Long-term projections can be made, based on the assumption that current sex preferences remain unchanged (Caselli and Vallin 2001). They show that an unbalanced population may be sustainable on a purely demographic basis, but that a large surplus of men may be the source of many social problems (a surplus of women being less likely to occur). Last but not least, sex-selective abortions may lead to eugenics, a practice of sinister repute in Europe (Demeny 2005).

There was a general feeling that such a disequilibrium is detrimental to populations, but on the question of whether prenatal diagnosis and selective abortions must (or can) be avoided, the demographers did not have much to say. On the one side, some argued in favor of maintaining the "natural" equilibrium, using arguments extremely similar to those used in the past against fertility control. On a purely logical basis, if couples cannot choose the sex of their children, why should they be able to choose the number of children they have? On the other side, others claimed that banning sex selection is not feasible, as illegal practices are common; and that some countries have already experienced a transitory unbalance, followed by a return to equilibrium, making long-term assumptions unreliable. The relationship between demographic diagnosis at the macro level and rules regulating individual behaviors appeared to be, in that debate as in others, a non-demographic question.

\subsubsection{What are the consequences of policies?}

All in all, demographers are not experts in assessing public policies. Demographers can try to estimate the demographic consequences of different policy measures, but taking into account all consequences of each measure is not easy.

The question of equity is most often absent from demographic thinking, though central in terms of political action. Saying that the country needs more births says nothing about the types of families that are best at bearing and raising children. The 
question of social equity and organization is at stake here: Do we want to encourage specific groups of people to have more children?

\subsubsection{Conclusion: We should stick to answering research questions!}

The conclusion of this preliminary overview is straightforward: We as demographers should stick to what we are good at; namely, seeking to describe and understand past and current trends and to anticipate the future as far as we can. We should forget about giving advice to politicians.

\section{When the question comes to the floor}

So we could stay in our ivory tower, and everything would be simple. But in practice, we as scholars are sometimes asked questions. It is of course more comfortable not to answer, but our interlocutors (politicians, journalists, teachers, colleagues) often want a definite answer one way or the other.

\subsection{Do we have to answer?}

If demographers are not better experts than others, they may not be worse experts; what's more, our funding is often linked with the assumed usefulness of our work in nurturing public debate and in furthering political action.

\subsubsection{A general feeling that fertility is too low}

The diagnosis that European fertility is too low is now extremely widespread among European politicians and journalists (European Commission 2005). In France we have a long tradition of concern about the shortfall of births, and the current situation is a mix of an ongoing feeling that the country has a birth deficit, and pride in having the highest fertility in the European Union, except Ireland. This feeling is not unjustified, as shown by the central scenario of the French official population projections that assumed to be the most likely, based on the stability of current trends. They forecast a constant population at ages $0-60$, and a growing elderly population thanks to mortality decline and to a short-term lagged effect of the baby boom (Robert-Bobée 2006). But in most 
European countries, and in the EU as a whole (European Commission 2005), low fertility may lead to population decline, and there is now a general consensus in Europe that fertility is too low.

In response to this consensus, we may argue that there is no justification for public policy; ${ }^{6}$ or, if we think that there is room for policy, we must be ready to answer questions about which policies to promote.

\subsubsection{Enlighten public opinion with simple facts}

In order to answer the question about different policy options, we have to nurture public debate with facts that are as simple and clear as possible. The more sophisticated our reasoning, the higher the risk that it will be misunderstood or badly communicated. We all know the rules when speaking to journalists: no long sentences, no double negatives, no parenthetical clauses, etc.

Our reasoning thus has to be concentrated on simple facts that nobody can deny, and that may shed light on the debate. For instance, the current trend of population aging is by no means the consequence of the current low fertility, and the current or short-term future difficulties faced by our pension systems will surely not been solved by an increase in fertility. The same is true for the health system.

The fertility level has consequences only over the long term. In many European countries, the problem is made more acute by the fact that smaller cohorts born after the baby boom are now reaching reproductive ages: negative population momentum is being created, and there is a fear of a vicious circle called the "low fertility trap" (Lutz and Skirbekk 2005; Lutz, Skirbekk, and Testa 2006), whereby lasting low fertility could lead to lower fertility intentions among young couples.

\subsubsection{Be aware that we act as individuals}

Last but not least, we must always keep in mind that we answer as individuals, not as "the mouthpiece of Science." Our feelings about what is good for society as a wholei.e., our political and ideological orientations - inevitably guide our preferences with respect to the many possible means for raising fertility levels.

\footnotetext{
${ }^{6}$ This might be the case in France, where there is no strong reason for basing a population policy on the diagnosis that the country has a birth deficit. But in countries where the TFR is far below two, such an argument would be unlikely to convince a politician.
} 


\subsection{What should we answer?}

Family structures and behaviors have dramatically changed since the 1960s. Women's empowerment is one of the key aspects of that change. It seems that in many countries these trends are leading to low fertility. Two overall diagnoses are possible. The first is that the current trend is a move towards lasting low fertility, or endlessly decreasing fertility. Under this assumption, we need to go back to the "good old days" of the baby boom, when no contraception was available, when women had to obey their husbands, etc. Or, if no response is possible, we have to despair, waiting for the end of European populations... Another assumption is that the current situation is transitory, and that we have to accelerate the trend in order to reach the end of the transition and establish a new equilibrium at which fertility would be higher.

\subsubsection{New family forms and fertility levels?}

The relationship between new family forms (unmarried couples, lone families, etc.) and fertility is not straightforward. France, for instance, is experiencing similar family changes to other European countries, while maintaining stable and high fertility and avoiding the low fertility episodes observed elsewhere.

Cross-country comparisons seem to indicate that countries where non-marital births and divorce are more frequent, or where marriages and births are delayed, now exhibit the highest TFR. Even if part of the new correlation is spurious, there has nonetheless been a reversal of these correlations, from negative during the 1960s to null or positive in the late 1990s (Prskawetz, Mamolo, and Engelhardt 2006). So the arguments based on a nostalgic description of "the good old days" are not supported by the evidence. The opposite is not necessarily true, but high fertility is not systematically linked with early and universal marriage, low divorce rates, early first births, etc.

Many politicians or journalists may see fertility as a proxy for the relative merits of new family forms: for example, if unmarried couples have as many children as married couples, then the rise in unmarried cohabitation is seen as a positive trend...

\subsubsection{Raising the question to the institutional level}

Facing this temptation to judge individual behaviors, we would do better to position the debate at the macro level. We do not pinpoint the relationship between a specific family or social behaviour and the corresponding fertility level, but we describe relations at the macro level; i.e., how social conditions and family behaviors are related to the overall 
level of fertility. The question is thus not to urge couples to have more children, but to change the conditions at the national level so that there are more births in the country.

\subsubsection{Macro-level evidence: Countries where female labor force participation or gender equality are the highest have higher fertility}

At the macro level, one relationship is very enlightening: the higher the female labor force participation (FLFP), the higher the fertility level (Rindfuss, Guzzo, and Morgan 2003; Engelhardt and Prskawetz 2004). This relationship has reversed in the recent period, and it is easily understood: in European countries, women want to work (or couples want both partners to work). In countries where it is difficult to reconcile work and family life, both FLFP and TFR are low compared to other countries where reconciliation is easier.

The reversal in the correlation mainly comes from the fact that, in Southern European countries, FLFP has not increased much and is still low, while TFR has decreased dramatically. In Europe, high fertility is now positively correlated at the country level with high FLFP, and the correlation has also become zero or positive between high fertility and low marriage rates, high divorce rates, and a high proportion of extramarital births (Billari and Kohler 2004).

I will not elaborate on this evidence, as Livia Olah will describe it in detail [she did so during the debate; see her contribution in the same issue, article 24-9].

\section{Governments in Europe should be more aggressive in pushing for gender equality to raise fertility}

\subsection{The content of pronatalist policies}

\subsubsection{The need for consensus}

Let us assume that we want to push for a pronatalist policy. This policy must be based on strong public consensus, because it deals with very intimate matters.

\subsubsection{Long-term government commitment}

To be effective, the state commitment must extend over a long period, because people who are hesitating about having babies know that their children will remain dependent 
for many years. People must therefore be confident that this kind of policy measure will remain in force well into the future.

\subsubsection{Policies at the macro level, "child-friendly society"}

A good umbrella concept for a pronatalist policy is to create a "child-friendly" society. Children not only need to be born; they also have to be raised. The state can promise to assume its share of the burden so that the children can be raised under favorable conditions.

\subsubsection{Social differentials}

We saw that, in some countries, state support is directed towards children living in poor families, while in others the state wants to help all children in the same way, or support increases with parental income. This question is very controversial, and consensus is difficult to reach: family policy measures are not neutral in terms of social inequalities and equity. In France, the idea that the policies are universal, and that the state helps all families and all children, is very important for maintaining consensus (Aglietta, Blanchet, and Héran 2002).

\subsubsection{Population policies without side effects?}

A pronatalist policy can be based on two very simple premises. First, couples with children are useful for the country. Second, with these couples, mothers are the ones who face specific difficulties. It may thus be useful to do something to help mothers during the years when the couples are raising children. Political action must be based on a broad consensus. Negative side effects must also be very limited, to ensure sustainability.

\subsection{Gender equality as a pathway to consensus}

In order to implement a series of pronatalist policy measures, a global umbrella concept is needed. Gender equality, as a complement to a child-friendly society, is a very good candidate. It is a long-term objective which can be implemented in many ways. It 
concerns the overall organization of society, including cultural behaviors, and is not focused on individual matters and private choices.

\subsubsection{Pushing for gender equality is an efficient way to raise fertility}

At the individual level, egalitarian attitudes may not be correlated with earlier or higher fertility. For instance, Bernhardt and Goldscheider (2006) show that, in Sweden, "egalitarian men" have lower first birth fertility at the individual level. They conclude that, even in Sweden, "negotiating shared parenthood is still sufficiently difficult that it depresses fertility, but now because of its impact on men." The recent positive correlation between egalitarian attitudes towards family roles and fertility at the country level is a matter of context, and is compatible with such negative correlations at the individual level (Rindfuss, Guzzo, and Morgan 2003).

In evaluating fertility policies in different countries, Neyer (2006) shows the impact of the overall context. The efficiency of pronatalist policies depends on women's access to work before raising children, and the security of their ability to return to work after maternity leave, which is, in turn, conditioned by the availability of child care services. Similarly, a comparison of fertility and the costs of children in the USA and four European countries confirms the importance of the institutional context (DiPrete et al. 2003). The legitimacy of a mother's working when her children are still young is a primary factor in fertility; this is not an individual matter, but a country-level feature of social attitudes expressed by individuals, as well as by employers.

We must therefore think about family policies in terms of their impact at the country level. Policies oriented to gender equality are the only ones which may reduce the opportunity costs for couples, beyond economic evidence in the short term. A strong emphasis on child-friendly policies and family policies oriented towards gender equality is currently the only reliable basis for persuading women that having children will not be too costly for them in the long run.

The same is true for attitudes. In most countries, attitudes in favor of gender equality and high fertility intentions may be negatively correlated, but, from one country to the next, the mean ideal family size and egalitarian attitudes towards gender roles in family lives are positively correlated (Testa 2007). Fertility change is a matter of institutional change (Morgan and Taylor 2006), and gender equality is set to increase in Europe. The aim of policies must be to accompany this move towards more gender equality to make it more compatible with childbearing and childrearing. 


\subsubsection{Gender equality is a convenient political aim}

Morgan (2003) points out that "[a] coalition of those concerned about low fertility, the welfare of children, the stress of the second shift, and gender equality could press for institutional adjustments that improve the quality of life for mothers, fathers, children, and families." All these aims may be put under the final overarching concept: gender equality, which is the key for all these changes.

McDonald (2000) emphasizes that "incoherence between the levels of gender equity applying in different social institutions" can explain very low fertility: if gender equality is low in institutions focusing on families, and high in institutions that deal with people as individuals, women may choose to escape from the family trap by avoiding marriage, and, even more so, by avoiding motherhood.

A policy oriented towards gender equality must therefore allow women to behave as adult individuals in the family, as well as in other social institutions, not only in order for women to have children, but also for them to be able to enjoy full citizenship. Child-friendly policies, policies encouraging female labor force participation, labor market accommodation of voluntary part-time working, increasing income and work opportunity equality between men and women, and proactive policies encouraging fathers to share the burden of raising children, are different elements of a global set which constitutes a consistent political aim. The need for not-too-low fertility may be a good rationale and justification for such policies.

\subsection{Conclusion: Be brave, but be careful}

When politicians ask us about ways to raise fertility in Europe, we can thus agree that governments in Europe should be more aggressive in pushing for gender equality to raise fertility. Opportunity costs of childbearing are currently much higher for women than for men. This can be changed. Men have to take their share of the family burden, while women have to go on participating in the labor force, so that differences between men and women decrease. And this could lead to an increase in fertility.

Gender equality is not only a matter of motherhood and increasing fertility. It is a goal which has few negative side effects. It is an objective per se. Arguing for gender equality in order to increase fertility is also a means to create a family policy which would not necessarily be associated with a conservative vision of family behavior.

Another important question concerns which parents and which children we want to help. Pushing for gender equality has the great advantage of putting forward a global objective at the societal level, but, in practice, different policy measures will have very different "non-demographic" consequences. 
Toulemon: Rostock Debate, first YES: European governments must be more aggressive for gender equality

So, let us make things simple: Yes, governments in Europe should definitely be more aggressive in pushing for gender equality to raise fertility! 


\section{References}

Aglietta, M., Blanchet, D., and Héran, F. (2002). Démographie et économie. Rapports du Conseil d'analyse économique. Paris: La documentation française. $\left(\mathrm{n}^{\circ} 35\right.$, 340 pages) http://www.ladocumentationfrancaise.fr/rapports-publics/024000104/ index.shtml.

Bernhardt, E. and Goldscheider, F. (2006). Gender equality, parenthood attitudes, and first births in Sweden. Vienna Yearbook of Population Research 2006: 19-39. http://hw.oeaw.ac.at/0xc1aa500d_0x00144e0e.

Billari, F. and Kohler, H.-P. (2004). Patterns of low and lowest-low fertility in Europe. Population Studies 58(2): 161-176. (Erratum in Billari, F. and Kohler, H.-P. (2005). Reply to the note by Frejka and Sardon on our paper 'Patterns of low and lowest-low fertility in Europe' and an erratum. Population Studies 59(2): 239 245.). doi:10.1080/0032472042000213695, doi:10.1080/00324720500099843.

Caselli, G. and Vallin, J. (2001). Demographic trends: Beyond the limits? Population an English selection 13(1): 41-71.

Demeny, P. (2005). Ethical and political constraints on public choices in the field of fertility. Genus 61(3/4): 331-345.

DiPrete, T., Morgan, P., Engelhardt, H., and Paclova, H. (2003). Do cross-national differences in the costs of children generate cross-national differences in fertility rates? Population Research and Policy Review 22(5-6): 439-477. doi:10.1023 /B:POPU.0000020961.89068.91.

Engelhardt, H. and Prskawetz, A. (2004). On the changing correlation between fertility and female employment over space and time. European Journal of Population 20(1): 35-62. doi:10.1023/B:EUJP.0000014543.95571.3b.

European Commission (2005). Green Paper "Confronting demographic change: A new solidarity between the generations". http://europa.eu/scadplus/leg/ en/cha/c10128.htm and http://eur-lex.europa.eu/LexUriServ/site/en/com/ 2005/com2005_0094en01.pdf.

Eurostat (2006). Long-term population projections at national level. Statistics in focus Population and social conditions 3.

Gauthier, A. (2007). The impact of family policies on fertility in industrialized countries: A review of the literature. Population Research and Policy Review 26(3): 323-346. doi:10.1007/s11113-007-9033-x. 
Goldstein, J., Lutz, W., and Testa, M.R. (2004). The emergence of sub-replacement family size ideals in Europe. Population Research and Policy Review 22(5-6): 479-496. doi:10.1023/B:POPU.0000020962.80895.4a.

Golini, A. (2003). Low fertility and policy responses in some developed countries, with special reference to Europe. Journal of Population and Social Security (Population) 1(Supplement): 446-475. http://www.ipss.go.jp/webjad/WebJournal.files/population/2003_6/17.Golini.pdf.

IUSSP (2005). IUSSP population conference debate on the choice of the sex of children. http://iussp2005. princeton.edu/sessionViewer.aspx?sessionId=1218, $\mathrm{http}: / / \mathrm{www}$. canalc2.tv/video.asp?langue $=$ en\&idVideo $=3819$.

Kohler, H.-P., Billari, F., and Ortega, J.A. (2002). The emergence of lowest-low fertility in Europe during the 1990s. Population and Development Review 28(4): 641-680. doi:10.1111/j.1728-4457.2002.00641.x.

Lutz, W. and Skirbekk, V. (2005). Policies addressing the tempo effect in low-fertility countries. Population and Development Review 31(4): 699-720. doi:10.1111/j.1728-4457.2005.00094.x.

Lutz, W., Skirbekk, V., and Testa, M.R. (2006). The low fertility trap hypothesis: Forces that may lead to further postponement and fewer births in Europe. Vienna Yearbook of Population Research 2006: 167-192. http://hw.oeaw.ac.at/0xc1aa500d_0x00144e25.

McDonald, P. (2000). Gender equity, social institutions and the future of fertility. Journal of Population Research 17(1): 1-16. doi:10.1007/BF03029445.

McDonald, P. (2003). Sustaining fertility through public policy: The range of options. Population - E 57(3): 417-446. doi:10.2307/3246634.

McDonald, P. (2005). Fertility and the State: The efficacy of policy. Population and Development Review 32(3): 485-510. doi:10.1111/j.1728-4457.2006.00134.x.

McDonald, P. (2006). An assessment of policies that support having children from the perspectives of equity, efficiency and efficacy. Vienna Yearbook of Population Research 2006: 213-234. http://hw.oeaw.ac.at/0xc1aa500d_0x00144e27. doi:10.1553/populationyearbook2006s213.

Morgan, S.P. (2003). Is low fertility a Twenty-First-century demographic crisis? Demography 40(4): 589-603. doi:10.1353/dem.2003.0037. 
Morgan, S.P. and Taylor, M.G. (2006). Low fertility at the turn of the Twenty-First Century. Annual Review of Sociology 32: 375-399. doi:10.1146/annurev.soc.31.041304.122220.

Neyer, G. (2006). Family policies and fertility in Europe: Fertility policies at the intersection of gender policies, employment policies and care policies. Rostock: Max Planck Institute for Demographic Research. (MPIDR Working Paper WP2006-010). http://www.demogr.mpg.de/papers/working/wp-2006-010.pdf.

Périvier, H. (2004). Emploi des mères et garde des jeunes enfants en Europe. Revue de l'OFCE 90: 225-258. doi:10.3917/reof.090.0225.

Prskawetz, A., Mamolo, M., and Engelhardt, H. (2006). Reconsidering the relation between fertility and key fertility-related demographic behaviour across space and time. Vienna: Vienna Institute of Demography. (VID Working papers 09/2006). http://www.oeaw.ac.at/vid/download/WP2006_09.pdf.

Quesnel-Vallée, A. and Morgan, S.P. (2003). Missing the target? Correspondence of fertility intentions and behavior in the U.S.. Population Research and Policy Review 22(5-6): 497-525. doi:10.1023/B:POPU.0000021074.33415.c1.

Rindfuss, R., Guzzo, K., and Morgan, S.P. (2003). The changing institutional context of low fertility. Population Research and Policy Review 22(5-6): 411-438. doi:10.1023/B:POPU.0000020877.96401.b3.

Robert-Bobée, I. (2006). Projections de population pour la France métropolitaine à l'horizon 2050 - La population continue de croître et le vieillissement se poursuit. Insee première $1089 . \quad \mathrm{http} / / / \mathrm{www}$. insee.fr /fr/ffc/ipweb/ip1089/ip1089.pdf

Teitelbaum, M. and Winter, J. (1985). The fear of population decline. Orlando: Academic Press: 201 p.

Testa, M.R. (2007). Childbearing preferences and family issues in Europe: Evidence from the Eurobarometer 2006 survey. Vienna Yearbook of Population Research 2007: 357-379. http://www.oeaw.ac.at/vid/publications/ VYPR2007/Yearbook2007_Data-Trends_Testa_pp357-379.pdf. doi:10.1553/ populationyearbook2007s $3 \overline{5} 7$.

Toulemon, L. and Leridon, H. (1999). La famille idéale : combien d'enfants, à quel âge? Insee première 652. http://www.insee.fr/fr/ffc/docs_ffc/IP652.pdf.

Toulemon, L. and Robert-Bobée, I. (2006). The French population projected to level off at 70 million. Population and Societies 429: 1-4. 
Toulemon: Rostock Debate, first YES: European governments must be more aggressive for gender equality

United Nations (2007). World population prospects. The 2006 revision. http://esa.un.org/unpp/

van de Kaa, D. (2006). Temporarily new: On low fertility and prospect of pro-natal policies. Vienna Yearbook of Population Research 2006: 213-234. http://hw.oe aw.ac.at/0xc1aa500d_0x00144e26. doi:10.1553/populationyearbook2006s193. 